temperature the results are more difficultito interpret; while nitrogen maintains its nearly constant value for P.V., helium decreases rapidly, then increases, and the satne peculiarity is to be remarked with the other gases, although they do not give the product of $\mathrm{P}$.V. coinciding with that calculable by assuming that the increase of P.V. is proportional to the rise of absolute temperature.

These last experiments must be taken as merely preliminary ; but they show that further research in this direction would be productive of interesting results.

The spectra of these gases have been accurately measured by Mr. E. C. C. Baly, with a Kowland's grating; the results of his measurements will shortly be published. It may be remarked, however, that the colour of a neon-tube is extremely brilliant and of an orange-pink hue; it resembles nothing so much as a flame; and it is characterised by a multitude of intense orange and yellow lines; that of krypton is pale violet ; and that of xenon is sky-blue. The paper contains plates showing the most brilliant lines of the visible spectrum.

That the gases form a series in the periodic table, between that of fluorine and that of sodium, is proved by three lines of argument :-

(I) The ratio between their specific heats at constant pressure and constant volume is $\mathrm{I} \cdot 66$.

(2) If the densitues be regarded as identical with the atomic weights, as in the case with diatomic gases such as hydrogen, oxygen and nitrogen, there is no place for these elements in the periodic table. The group of elements which includes them is:-

$\begin{array}{cccc}\text { Hydrugen. } & \text { Helium. } & \text { Lithium. } & \text { Beryllium. } \\ \text { I } & 4 & 7 & 9 \\ \text { Fluorine. } & \text { Neon. } & \text { Sodium. } & \text { Magnesium. } \\ 18 & 20 & 23 & 24 \\ \text { Chlorine. } & \text { Argon. } & \text { Potassium. } & \text { Calcium. } \\ 35^{\circ} 5 & 40 & 39 & 40 \\ \text { Bromine. } & \text { Krypton. } & \text { Rubidium. } & \text { Strontium. } \\ 80 & 82 & 85 & 87 \\ \text { Iodine. } & \text { Xenon. } & \text { Cærsium. } & \text { Barium. } \\ \text { I27 } & 128 & 133 & 137\end{array}$

(For arguments in favour of placing hydrogen at the head of the fluorine group of elements, see Orme Masson, Chem. News, vol. lxxiii., 1896, p. 283 ).

(3) These elements exhibit gradations in properties such as refractive index, atomic volume, melting-point and boiling. point, which find a fitting place on diagrams showing such periodic relations. Some of these diagrams are reproduced in the original paper. Thus the refractive equivalents are found at the lower apices of the descending curves; the atomic volumes, on the ascending branches, in appropriate positions and the melting- and boiling-points, like the refractivities, occupy positions at the lower apices.

Although, however, such regularity is to be noticed, similar to that which is found with other elements, we had entertained hopes that the simple nature of the molecules of the inactive gases might have thrown light on the puzzling incongruities of the periodic table. That hope has been disappointed. We have not been able to predict accurately any one of the properties of one of these gases from a knowledge of those of the others; an approximate guess is all that can be made. The conundrum of the periodic table has yet to be solved.

ACTION OF TERRESTRIAL MAGNETISM ON THE RATES OF CHRONOMETERS.

$\mathrm{I} \mathrm{N}$ the issue of the Comptes rendiss of the Paris Academy of

Sciences for November 26, vol. cxxxi., pp. 859-865, there is an important communication by l'rof. $\Lambda$. Cornu, dealing with an experimental investigation of the action of a terrestrial magnetic field on the rate of a magnetised chronometer.

The observations have been carried out on a pocket halfchronometer, provided with anchor-escapement, compensated balance and palladium spiral, whose rate had previously been very satisfactory, but which had inadvertently become magnetised by a large electro-magnet. The generally prevalent idea is that a magnetised watch is quite untrustworthy until it has been completely demagnetised, but the author's research has con. vinced him that there is evidence of a regular law in the rate of such an affected timepiece, and therefore it should be possible

No. $\llbracket 624$, VOL. 63 to neutralise the disturbance, either by tables of correction formulæ, or by suitably disposed compensators.

The magnetisable parts are the pivots, anchor, spring, balancewheel and accessories to the escapement. In watches of precision all direct contacts between steel parts are avoided by the use of hard stone bearings, so that the mutual actions are inductive effects. If, then, the watch be laid on a horizontal table at a definite orientation, the only disturbing external force capable of affecting its rate will be the terrestrial magnetic field. To test this, provision was made for varying the orientation of the balance by making the horizontal support movable about a vertical axis, and then keeping the watch or clock for several days successively in the four positions corresponding to the hours XII, III, VI, IX, pointing respectively to the IIagnetic North.

Systematic observations from I 898 June 20 to 1900 November 17 , furnish a series of values for the variations in rate at the four orientations, and the discussion of them has enabled Prof. Cornu to show that they may be represented by a sinusoid. The magnetic state of the watch remains sensibly constant; the semi-amplitude of the variations with the orientation was 10.37 secs., and the mean azimuth of the ascending node of the sinusoid about $260^{\circ} 21^{\prime}$. This result is especially interesting and important in that this sinusoidal law is identical with that obtaining when a watch having a balance wheel slightly out of equilibrium is hung with its dial vertical and oriented to different azimuths. That is, gravity also produces, if the mean amplitude remains constant, a couple proportional to the vertical projection of the eccentricity of the centre of gravity. IIere a series of observations of the rate of the same watch before it was magnetised are given, taken during the period $x 890$ October 26-1891 January 25, showing the fulfilment of the sinusoid law in this respect.

It would thus appear that the condition discovered by Phillips (Annales des Mines, 6th series, vol. ix., p. 321, 1866) for elimin ating the disturbance due to gravitation may also be applied to the compensation for magnetisation.

As a crucial test of the truth of his deductions, Prof. Cornu performed a substitution experiment in which the earth's mag. netism was directly allowed for. In a piece of cork of exactly the same form as the watch a cylindrical hole was cut in the position corresponding to the balance wheel. In this was supported a small compass needle, and the whole supported on a horizontal table. By means of a jointed arm a bar magnet was held in such a position that the earth's magnetisn was neutralised, leaving the needle astatic. This done, the watch was substituted for the cork, the orientation of the balance whee being the same as the small compass in the cork. This substitution of cork model, getting astatic position by bar magnet, and replacement of watch, was repeated for the four orientations, and the daily rate carefully determined. It was found to be sensibly constant in all positions.

The paper concludes with the following summary :-

(I) Chronometers of precision are influenced by variations of the magnetic field in which they are placed to an amount depending on the degree of magnetisation of the balance wheel and spring

(2) It is important to determine the magnetic moment of the balance wheel, mounted or not on the spiral.

(3) In observatories studying chronometer rates it is necessary to regularly determine the comparative variations in four rectangular aximuths for calculating the formulx of correction.

(4) In all cases it should be the endeavour to attain an amplitude of $440^{\circ}$ for the oscillations of the balance wheel, as recommended by Phillips, to eliminate the action of the terrestrial magnetic couples.

(5) For precaution, in observatories as well as on board ship, it would be well to envelop each chrononeter with a thick box of iron, so that the relative action of the terrestrial field may be lessened.

C. P. 13 .

\section{THE EFFECTS OF AN EARTHQUAKE ON} HUMAN BEINGS.

CAPTAIN IDUTTON'S valuable memoir on the Charleston earthquake of I 886 contains many accounts of the effects of this great earthquake on human beings. Nowhere could they be more vivid than in Charleston itself. "On every side," says one witness, "were hurrying forms of men and women, bareheaded, partially dressed, some almost nude [the earthquake 
occurred at $9.5 \mathrm{I}$ p.m.], and all nearly crazed with fear and excitement. . . . A few steps away, under the gas-lamp, a woman lies prone and motionless on the pavement, with upturned face and outstretched limbs, and the crowd which has now gathered in the street passes her by, none pausing to see whether she is alive or dead . . .; ; many voices are speaking at once, but few heed what is said." Between this, which must surely be almost the limit of wild fear in a crowd, and the merely interested curiosity of the most distant observers, there seems to be nearly every stage of mental effect recorded. Such terms as "greatest consternation," "fright and excitement unparalleled," and "terror amounting to wild frenzy," are, of course, too dependent on the narrator and too vague to be of any value as degrees in a scale of mental effects; but the resulting actions are less liable to error or exaggeration, and these may be roughly classified as follows, the different degrees being lettered to avoid confusion with the numbers of the soseismal lines:

(A) No persons leave their rooms.

(B) Some persons leave their houses.

(C) Most persons run into the streets, which are full of excited people.

(D) People rush wildly for open spaces, and remain all night out of doors.

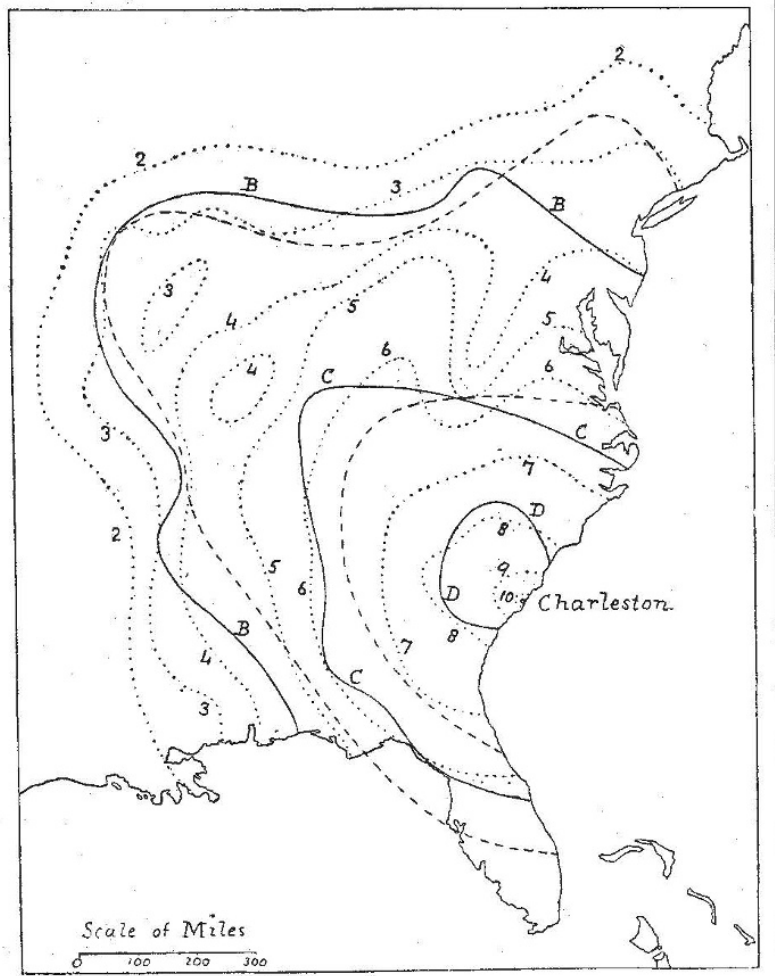

In the third degree of the scale, I included at first the hasty dispersal of meetings; but, when the places at which this occurred are plotted on a map, it is evident that this effect would find an appropriate place under the second heading. A crowd in one room is more liable to excitement and fear than are persons in separate houses.

In the accompanying map, the dotted curves are the isoseismal lines as drawn by Captain Dutton. The continuous curves bound the areas in which the effects corresponding to the three higher degrees of the scale were observed. The curve for the first degree of course coincides with the outermost isoseismal line.

It will be seen that there is a certain rough agreement between these curves and the isoseismal lines. The curve $\mathrm{D}$ and the isoseismal 8 are not far apart; in other words, if the shock was strong enough to throw down chimneys or make cracks in the walls of buildings, then people thought it wiser to camp out for the night. The curve $\mathrm{c}$ and the isoseismal 6 coincide approximately; that is, people rushed precipitately into the streets if the movement made chandeliers, pictures, \&c., swing. No, I624, VOL. 637
On the whole, the curve B roughly follows the isoseismal 3 ; so that, if the shock was not even strong enough to cause doors and windows to rattle, some persons were so alarmed that they left their houses, and public meetings were dispersed. Whether these effects were due to the rarity of the phenomenon or to the highly-strung nerves of the American people, it may, I think, be inferred that in no other civilised country would such alarm be shown at a sudden and unexpected occurrence.

Captain Dutton also gives many records of a feeling of nausea at the time of the earthquake; and, however excitable the observers may have been, these accounts are probably trustworthy, for this is not at all generally known to be a result of earthquake-motion. I have marked these places on a map, and it is curious that, with one or two exceptions, they all lie between the two broken lines of the figure. The most distant places at which the feeling wàs noticed are Blue Mountain Creek (New York), 823 miles, and Dubuque (Iowa), 886 miles, from Charleston. The outer boundary of the nausea area follows roughly the curve $B$, but is generally inside it; the inner boundary is so close to the curve $\mathrm{C}$ as to suggest that there may be some connection between them, that, in the wild hurry to reach the stre:t, the slight feeling of nausea might escape notice.

\section{Charles Davison.}

\section{THE CAMBRIDGE SENTINEL MILK STERILISER.}

THIS is a simple and automatic milk steriliser for domestic use. It is made in three forms; in one, which is intended for use on an ordinary fire, a tube which carries an alarm bell at the top is inserted through the lid of the saucepan. When the desired temperature $\left(85^{\circ} \mathrm{C}\right.$. $)$ is reached, a trigger contained in the tube is automatically released, and the bell rings, thus warning the attendant to take theipan off the fire. In a second form the action is automatic. A saucepan containing the sensitive trigger is placed on a gas stove, and when the proper temperature is reached the release of the trigger causes the supply of gas to be automatically cut off. A third form is arranged for use with a spirit lamp. In each case, the automatic mechanism is actuated through the melting of an easily fusible alloy.

For the apparatus it is claimed ( 1 ) that it is simple and works automatically, (2) that the temperature $\left(85^{\circ} \mathrm{C}\right.$.) attained does not impair the flavour or the nutritive qualities of the milk, (3) that injurious micro-organisms, including tubercle, are destroyed. Dealing with these claims in order, the apparatus certainly acts automatically and seems to be of simple construction. With regard to the first or bell form, however, the sound of the bell is so slightly audible that it would certainly be missed unless the attendant were listening for it, and in all probability in nine cases out of ten the milk would be boiled. The second form, with gas stove and automatic cut-off, works quite well and is much to be preferred. With regard to the temperature at which the signal is given or the cut-off takes place there is some difference, according to the amount of fluid which is being treated. Dealing with the two-pint size we have observed the following temperatures :

\begin{tabular}{|c|c|c|c|c|}
\hline & & Bell Form. & & Cut-off Form. \\
\hline & & 94 and $95 \mathrm{C}$. & .......... & $95^{\circ}$ and $93^{\circ}$ \\
\hline & pint & $875^{\circ} \quad " 89$ & ....... & $", 87^{\circ}$ \\
\hline & fonst & , & …...... & \\
\hline Milk & Two pints & $\begin{array}{l}90 \\
87^{\circ}\end{array}$ & …… & $84^{\circ}$ \\
\hline
\end{tabular}

It will thus be seen that there is a considerable variation in the temperatures.

As to the second point, we consider that the temperature of $85^{\circ} \mathrm{C}$. is too high, and we believe that the experiments of Duclaux and others have conclusively shown that milk cannot be heated above $70^{\circ} \mathrm{C}$. without altering its flavour and nutritive qualities. Tested practically, milk heated in the apparatus and immediately cooled has a pronounced flavour, little less marked than milk which has been just boiled and then cooled. Three samples-(I) untreated, (2) sterilised in the apparatus and immediately cooled, (3) boiled and cooled - were submitted to three individuals, who separately tasted them; two of the individuals were unable to distinguish between the sterilised and boiled samples; the third said "that the sterilised sample seemed a little less boiled than the other." The flavour being so markedly altered, we doubt whether the claim that the nutritive qualities of the milk are unchanged can be substantiated. 